\title{
EFFECT OF BUTANOL-DIESEL BLENDS IN A COMPRESSION IGNITION ENGINE TO REDUCE EMISSION
}

\author{
S. Sendilvelan* and K. Rajan \\ Department of Mechanical Engineering, Dr. M.G.R Educational and Research Institute, \\ Chennai-600 095 (Tamil Nadu) India. \\ *E-mail: sendilvelan.mech@drmgrdu.ac.in
}

\begin{abstract}
In this investigation butanol was added to diesel with known percentages to improve the performance of a diesel engine. To avoid separation, Span 80 emulsifier added to the oxygen enriched fuel with water to get suitable blends. The experiment has been conducted in a four stroke, single cylinder diesel engine having different loads at constant speed were investigated. The oxides of nitrogen, carbon monoxide, and smoke opacity were found to be minimum for D70 (70:29:1) blend compared with the other blends. The effect of butanol diesel blends is found to reduce smoke density and nitrogen oxide emissions from a diesel engine. The brake thermal efficiency of the butanol blends decreases with increase in butanol percentage in the blends. CO emission decreased by $42 \%$ and $14 \%$ for 80D and 75D blends respectively at full load. The HC emissions decreased by $30 \%$ and $31 \%$ for D80 and D75 blend at full load compared with neat diesel fuel. Smoke density decreased $20 \mathrm{HSU}$ at full load for D70 due to a complete combustion. The maximum $\mathrm{NO}_{\mathrm{x}}$ emission reduction of $29 \%$ for $\mathrm{D} 65$ and followed by $16 \%, 11 \%$ and $6 \%$ for D70, D75 and D80 blends respectively at full load.
\end{abstract}

Keywords: Butanol; Diesel Engine; Emission; Emulsifier; Oxygenated Fuel

(C) RASĀYAN. All rights reserved

\section{INTRODUCTION}

Due to the increasing cost and scarcity of petroleum product, efforts are on to develop alternative fuels. ${ }^{1}$ The diesel engine produce high thermal efficiency and lower carbon monoxide (CO) and hydrocarbon (HC) emissions, same time it produces more smoke, particulate matter (PM) and oxides of nitrogen (NOx) and it is difficult to simultaneously to reduces NOx and smoke density due to a trade-off between NOx and smoke. ${ }^{2}$ The reduction of NOx and smoke emissions by Exhaust Gas Recirculation (EGR), deNOx catalytic converter, high-pressure injection and oxygenated fuels were tried by many researchers. ${ }^{3}$

The major problem associated with diesel engine is the use of alcohol in higher percentage with diesel fuel. ${ }^{4}$ The limited capability of miscibility at a lower temperature and the required minimum modification in fuel delivery systems restrict the use of butanol in diesel fuel. Jimenez et al. studied the properties of ethanol-diesel fuel blends. ${ }^{5}$ Ashok has tested diesel engine performance, emission and combustion characteristics with ethanol-diesel emulsion. ${ }^{6}$ It was reported that thermal efficiency increases and decrease the fuel consumption, exhaust temperature, soot and nitrous oxides emissions at the maximum $\operatorname{load}^{7}$. Pradeep et al. identified the effects of using 5\% and $10 \%$ of n-butanol blends with Karanja oil methyl ester as an additive in a diesel engine ${ }^{8}$. Their results indicated that at high engine load the carbon monoxide (CO) was lower and Hydrocarbon (HC) emission was slightly higher for the blends of BDNB5 and BDNB10 as compared to biodiesel blend at full load. But the NOx emissions were lowered for the blends as compared to diesel and biodiesel blend at full load. ${ }^{9}$ Butanol is a renewable bio-fuel due to its hydrophilic properties with high heating value and cetane number. ${ }^{10}$ When the water content of the butanol is more than one percent this occurrence of this phenomena will be avoided with the use of additives. ${ }^{11}$

Span 80 (Sorbitan oleate) suitable surfactant with required qualities of good additive and miscible in diesel $0-35 \%$, the structural formula for Span 80 as shown in Figure-1. In this investigation, the emulsifying agent, called surfactant Span 80 of $1 \%$ by volume was added to the diesel-n-butanol blend

Rasayan J. Chem., 10(1), 190-194 (2017)

http://dx.doi.org/10.7324/RJC.2017.1011609 
and it was stirred at a constant speed of $5000 \mathrm{rpm}$ to make the required stable emulsion. Preparation of the butanol-diesel blends was carried out with $200 \mathrm{~cm}^{3}$ volume container. Butanol-diesel blends were mixed well in a laboratory mixer for 24 hours to get the stability of the emulsified mixtures. The following blends were prepared with diesel and butanol with 1\% Span 80; D80 (80\%D:19\%BUT:1\%SP), D75 (75\%D:24\%BUT:1\%SP), D70 (70\%D:29\%BUT:1\%SP) and D65 (D65-65D:34BUT:1SP). These emulsions were used to analyze the engine characteristics.

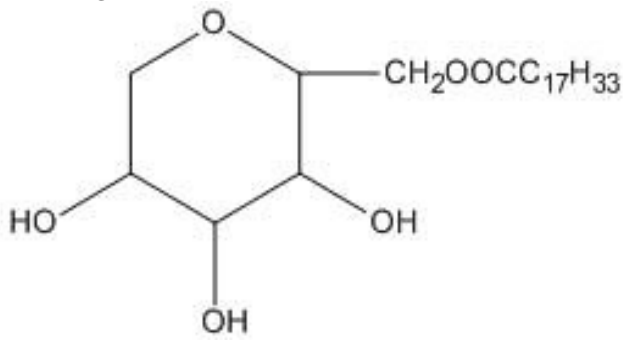

Fig.-1: Structural Formula; Span 80, Sorbitan Oleate

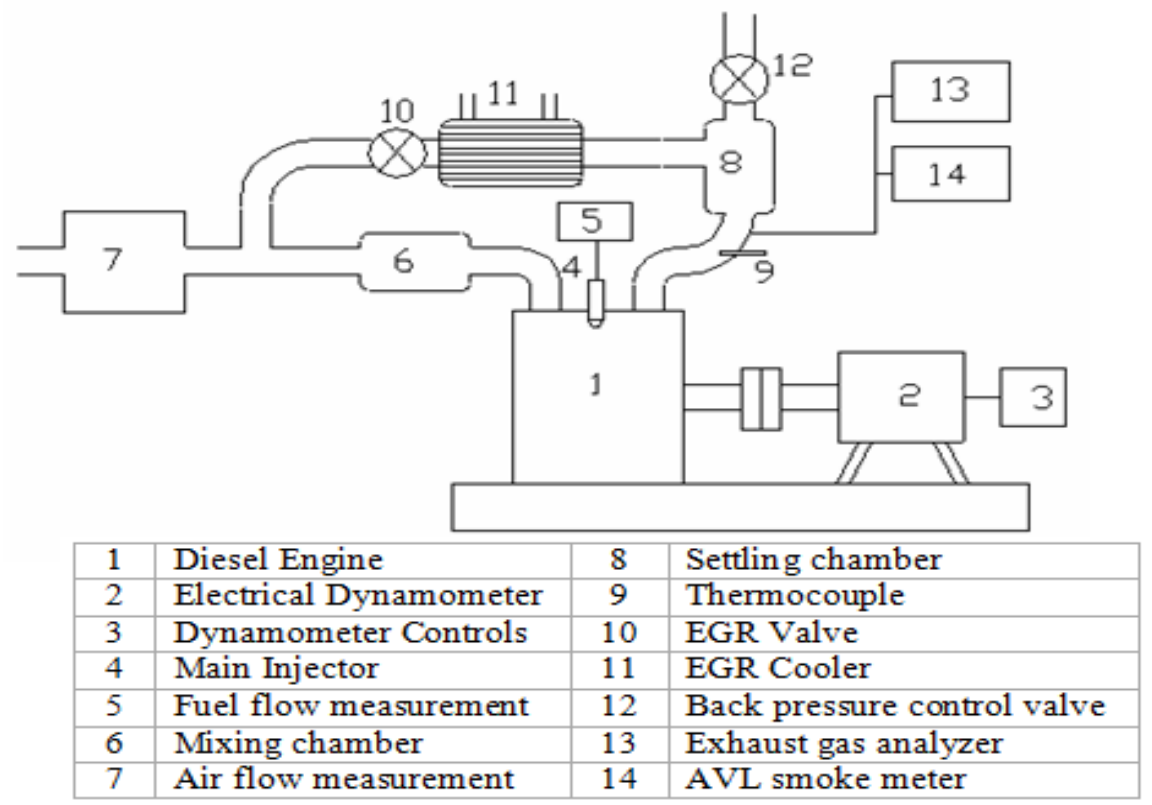

Fig.-2: Experimental Engine setup

\section{EXPERIMENTAL}

The experiment was conducted in a diesel engine with the rated power of $4.4 \mathrm{~kW}$ as shown in Figure- 2. The engine was operated at a speed of $1500 \mathrm{rpm}$. The experiment was carried out with butanol 20 to 35\% in the steps of 5\% Span 80 by volume to sole fuel. The measurements like fuel flow and exhaust emissions were recorded when the engine was operated with different loading conditions for each fuel. The engine performance was recorded with standard equipment. Initially with diesel as fuel all emissions vales were recorded, then with diesel $80 \%$ with $19 \%$ butanol with $1 \%$ Span 80 were recorded. In the same procedure, all the fuels were tested for emission characteristics. The brake thermal efficiency, CO, HC, NOx and smoke opacity were analyzed to compare with the sole diesel fuel.

\section{RESULTS AND DISCUSSION}

The brake thermal efficiency variation with load for diesel and butanol blends is shown in Figure-3. The maximum brake thermal efficiency obtained for the engine operating on D80, D75, D70 and D65 blends was $29.1 \%, 28 \%, 26.8 \%$ and $26 \%$ respectively and for diesel was $30.42 \%$ at full load. 
RASĀYAN $J$. Chem.

Vol. 10 | No. 1 |190-194 | January - March | 2017

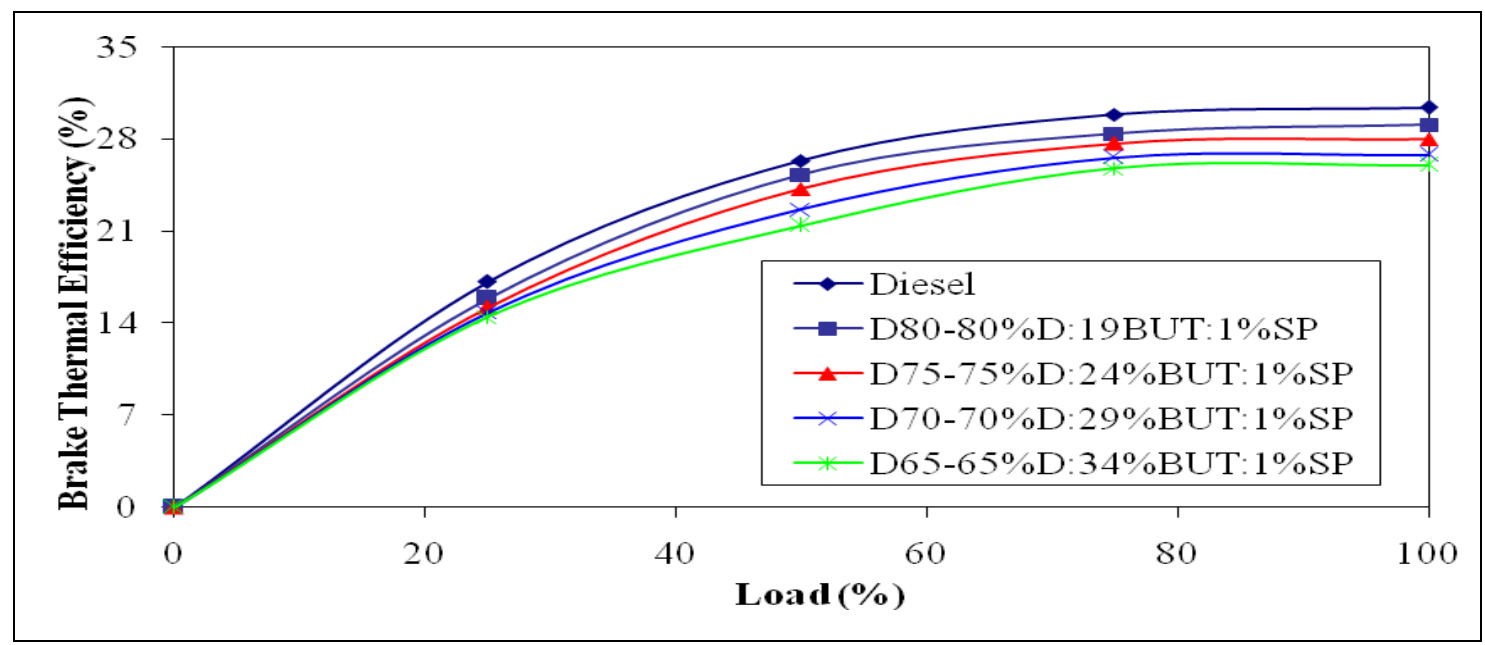

Fig.-3: Brake thermal efficiency variations with Load

The BTE of the butanol blends decreases with increase in proportions of butanol in the blends. The decrease in BTE may be due to the high latent heat of vaporization of butanol, which decreases the charge temperature, thus decreases the brake thermal efficiency ${ }^{12}$.

Figure-4 shows the carbon monoxide emissions variations for different butanol additions with load. The carbon monoxide value increases with increase in the butanol percentage in the diesel fuel. Among the blends 70D: 29BUT: 1SP ratio shows minimum carbon monoxide compared to fuel blends and neat diesel fuel. This decrease in $\mathrm{CO}$ emissions for lower butanol blends may be due to the oxygen availability. ${ }^{13}$ There is $42 \%$ and $14 \%$ decrease in CO emissions for $80 \mathrm{D}$, 75D and 70D blends respectively and 14\%, 21\% and 28\% respectively, whereas for D65, it increased by $29 \%$ blends respectively at full load compared with neat diesel fuel.

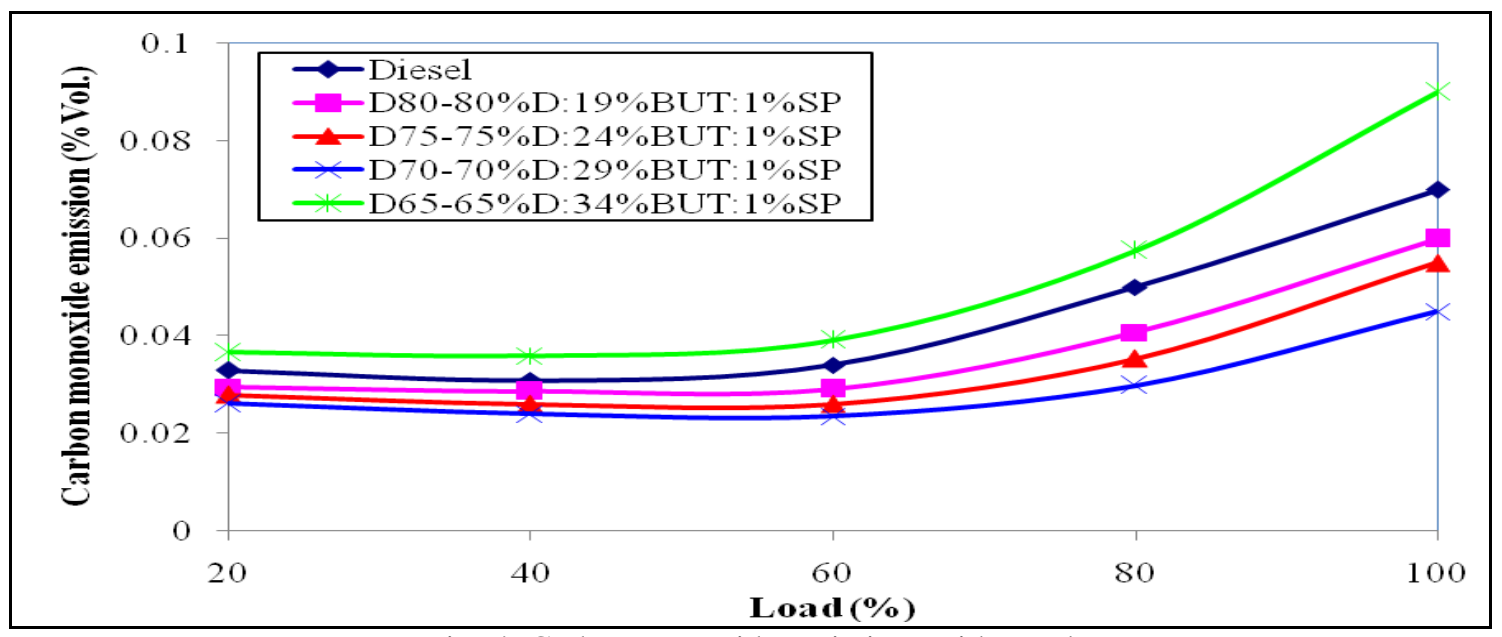

Fig.-4: Carbon monoxide variations with Load

Figure-5 illustrates the HC emission with different butanol blends with diesel. It was observed that HC emission with butanol blend slightly higher than neat diesel fuel. This is due to the higher heat of evaporation of butanol, which leads to increase in $\mathrm{HC}$ emission. ${ }^{14}$ It was observed that at lower percentage of butanol 19\% (D80) and 24\% (D75) in diesel, the HC emissions decreases and further it increases when the butanol percentage increase in the blend. The HC emissions decreased by $30 \%$ and $31 \%$ for D80 and D75 blend respectively and 27\% and 63\% increased for D70 and D65 blends respectively at full load compared with neat diesel fuel. 
RASĀYAN $J$. Chem.

Vol. 10 | No. 1 |190-194 | January - March | 2017

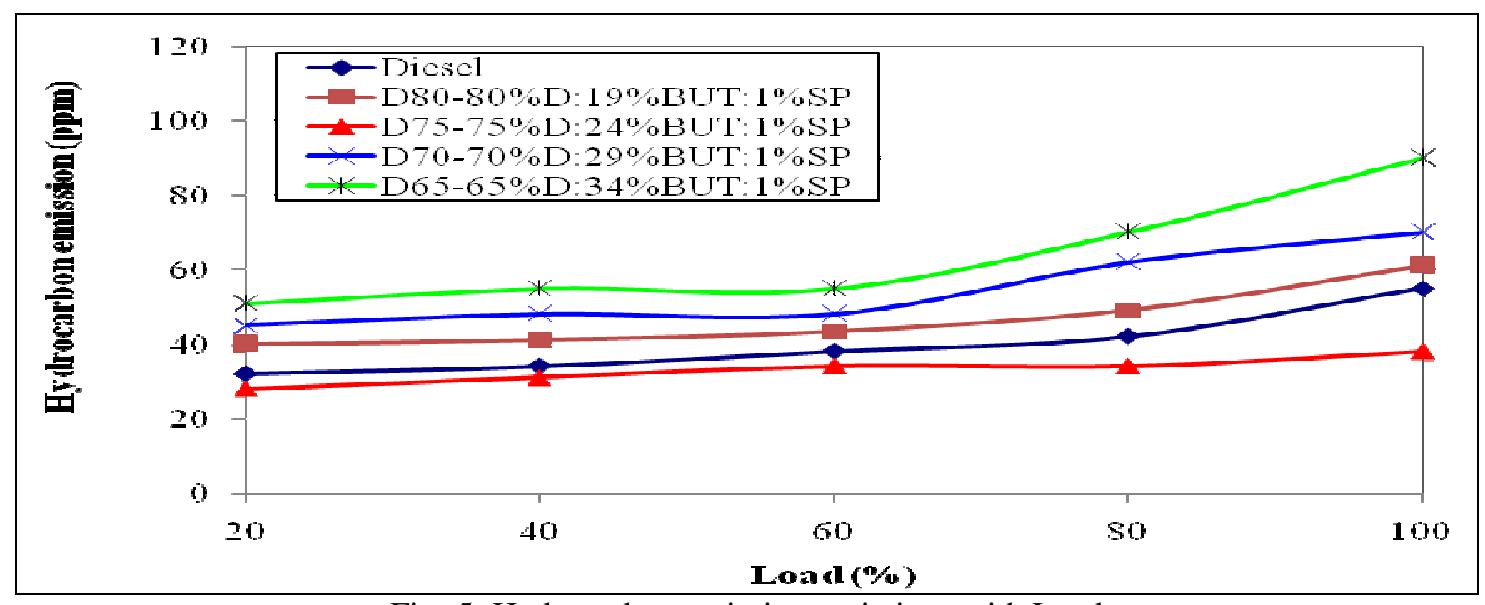

Fig.-5: Hydrocarbon emission variations with Load

Figure-6 illustrates the variations of NOx emission with load for the butanol blends and diesel. The NOx emission control depends on the combustion temperature, local counteraction of oxygen and duration of combustion ${ }^{15}$. It was found that NOx emission was increased gradually from no load to full load. At the rated output the value of NOx is lower than diesel at blends. It was observed that combustion pressure was reduced during this period which may be the reason for the NOx emission reduction. ${ }^{16}$ It was observed that there is a maximum 29\% reduction in NOx emission for D65 and followed by $16 \%, 11 \%$ and 6\% for D70, D75 and D80 blends respectively at full load. Lowest NOx emission obtained for D65, D70, D75 and D80 is 504ppm, 560ppm, 634ppm and 632ppm respectively at full load, whereas for diesel it was $714 \mathrm{ppm}$ at full load.

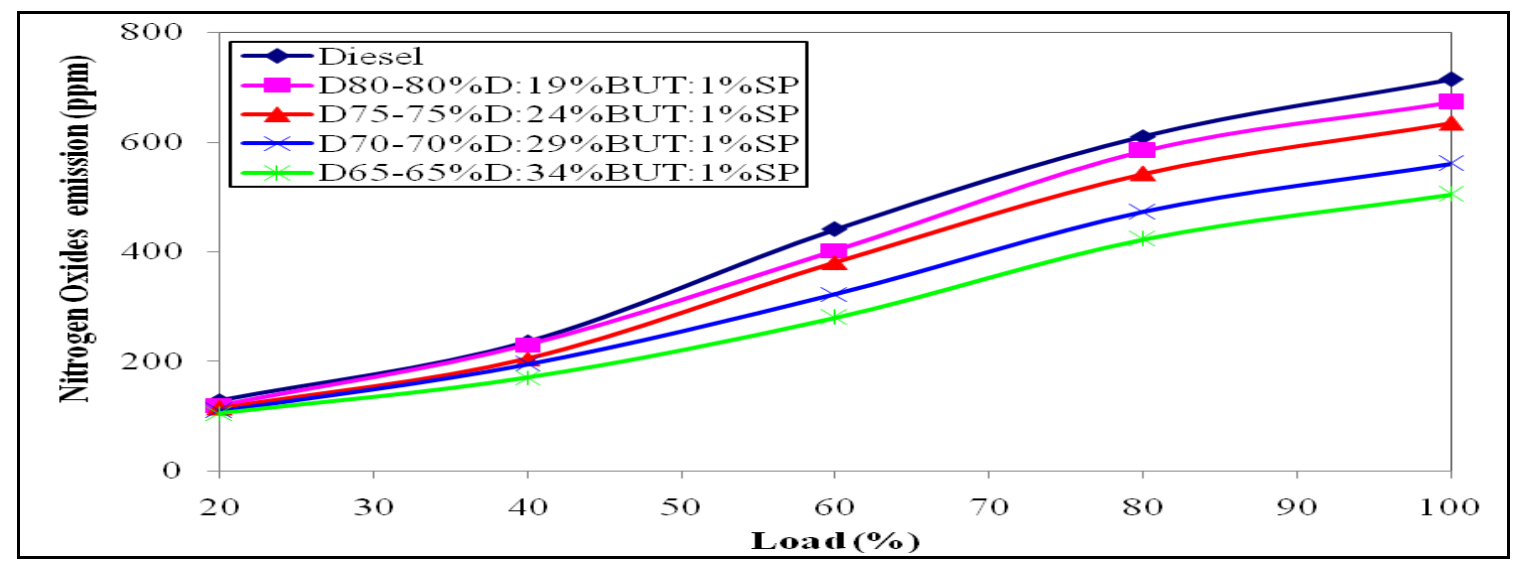

Fig.-6: Nitrogen oxides emission variations with Load

The variation of smoke density with respect to engine load is shown in Figure-7. The addition of butanol and Span, decreasing the smoke density especially at part load to maximum load ${ }^{16}$. The smoke density decreased $20 \mathrm{HSU}$ at full load for D70 because of increased heat release rate and a complete combustion. Therefore, butanol addition to diesel fuel was a more effective reduction of smoke density at lower blends in diesel and it was increased by 4 HSU for D65 blend compared to neat diesel fuel at full load.

\section{CONCLUSION}

The experimental investigations carried out in a diesel engine and various proportions of butanol-diesel blends such as D80, D75, D70 and D65 as a fuel. The brake thermal efficiency of the butanol blends decreases with increase in butanol percentage in the blends. Very low BTE was obtained for D70 (26.8\%) and D65 (26\%), for diesel it was $30.42 \%$ at full load. CO emission decreased by $42 \%$ and $14 \%$ 


\section{RASĀYAN J. Chem.}

Vol. 10 | No. 1 |190-194 | January - March | 2017

for $80 \mathrm{D}$ and 75D blends respectively and $14 \%$ and $28 \%$ increase in $\mathrm{CO}$ emissions for 70D and 65D blends respectively at full load. The HC emissions decreased by $30 \%$ and $31 \%$ for D80 and D75 blend respectively and 27\% and 63\% increased for D70 and D65 blends respectively at full load compared with neat diesel fuel. Smoke density decreased $20 \mathrm{HSU}$ at full load for D70 because of butanol contains more oxygen contents, resulting in a more complete combustion. The maximum $\mathrm{NO}_{\mathrm{x}}$ emission reduction of $29 \%$ for D65 and followed by 16\%, 11\% and 6\% for D70, D75 and D80 blends respectively at full load. Overall, the higher percentage alcohol fuel can be blended with diesel with the presence of surfactant Span 80, which simultaneously reduces the NOx and Smoke emissions.

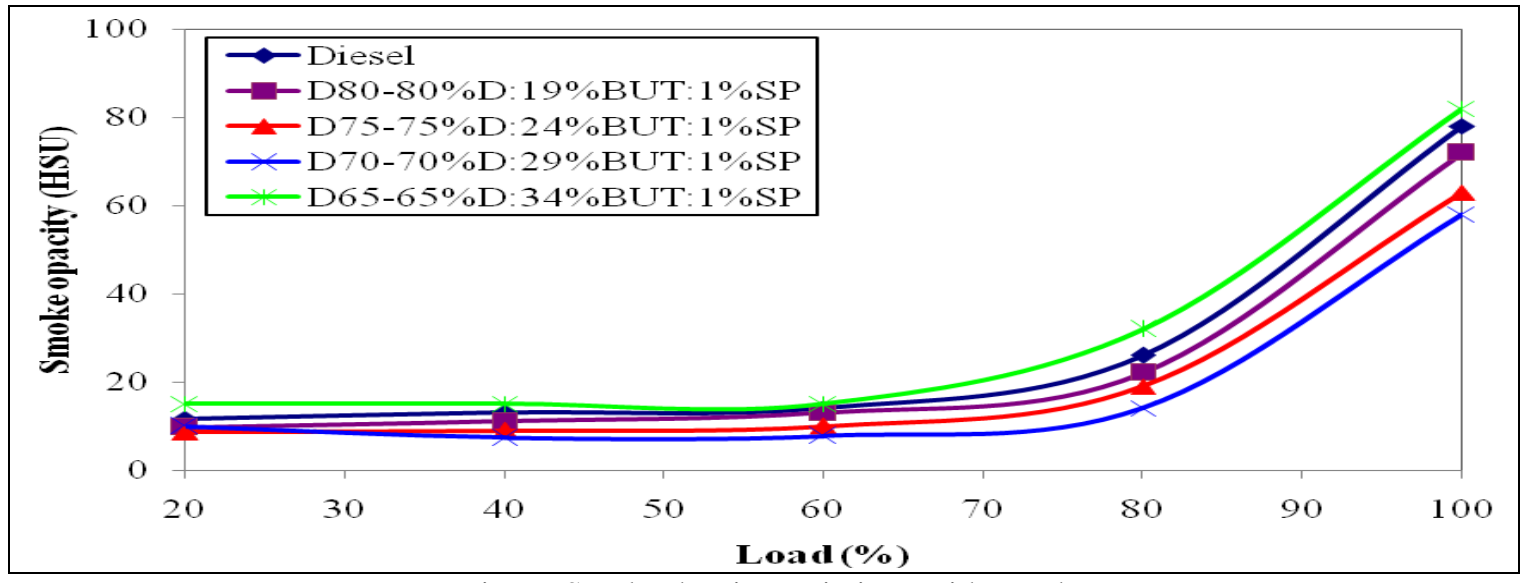

Fig.-7: Smoke density variations with Load

\section{REFERENCES}

1. D.C. Rakopoulos, C.D. Rakopoulos, E.G. Giakoumis, R.G. Papagiannakis, and D.C. Kyritsis, Energy, 73, 354 (2014)

2. C. Sundar Raj, S. Arul, S. Sendilvelan, C.G. Saravanan, Energy Sources, Part A: Recovery, Utilization and Environmental Effects, 32 (17), 1603 (2010)

3. F.J. Jiménez-Espadafor, M. Torres, J.A Velez, E. Carvajal, and J.A. Becerra, Fuel Processing Technology, 103, 57 (2012)

4. S. Kumar, J.H. Cho, J. Park, and I. Moon, Renewable and Sustainable Energy Reviews, 22, 46 (2013)

5. E. Torres-Jimenez, M.S. Jerman, A. Gregorc, I. Lisec, M.P. Dorado, and B. Kegl, Fuel, 90 (2), 795 (2011)

6. M.P. Ashok, Energy and Fuels, 25 (8), 3799 (2011)

7. S. Sendilvelan, and K. Bhaskar, Rasayan Journal of Chemistry, 9 (4), 692 (2016)

8. R. Pradeepraj, and K. Rajan, International Journal of Applied Engineering Research, 9 (18), 4369 (2014)

9. S. Sendilvelan, K. Bhaskar, Rasayan Journal of Chemistry, 10 (1), 111 (2017)

10. H. Sajjad, H.H. Masjuki, M. Varman, M.A. Kalam, M.I. Arbab, S. Imtenan, and S.M.A. Rahman, Renewable and Sustainable Energy Reviews, 30, 961 (2014)

11. D.C. Rakopoulos, C.D. Rakopoulos, E.G. Giakoumis, A.M. Dimaratos, and D.C. Kyritsis, Energy Conversion and Management, 51 (10), 1989 (2010)

12. O. Doğan, Fuel, 90 (7), 2467 (2011)

13. N. Yilmaz, F.M. Vigil, K. Benalil, S.M. Davis, and A. Calva, Fuel, 135, 46 (2014).

14. S.H. Park, I.M. Youn, and C.S. Lee, Fuel, 90 (2), 748 (2011)

15. S.M. Palash, M.A. Kalam, H.H. Masjuki, B.M. Masum, I.M. Rizwanul Fattah, and M. Mofijur, Renewable and Sustainable Energy Reviews, 23, 473 (2013)

16. Z.H. Zhang, S.M. Chua, and R. Balasubramanian, Fuel, 176, 40 (2016)

[RJC-1609/2017] 